\title{
Temporal variations in helium and argon isotopic compositions of fumarolic gases at Kusatsu-Shirane volcano, Japan
}

\author{
DR. TOMOYA OBASE, PHD $^{1}$, HIROCHIKA SUMINO ${ }^{1}$, \\ KOTARO TOYAMA ${ }^{2}$, TAKESHI OHBA ${ }^{3}$, MUGA \\ YAGUCHI $^{4}$ AND AKIHIKO TERADA ${ }^{5}$
}

${ }^{1}$ The University of Tokyo

${ }^{2}$ University of Tokyo

${ }^{3}$ Tokai University

${ }^{4}$ Meteorological Research Institute, Japan Meteorological Agency

${ }^{5}$ Volcanic Fluid Research Center, Tokyo Institute of Technology

Presenting Author: tomoyaobase@g.ecc.u-tokyo.ac.jp

The helium isotopic ratio $\left({ }^{3} \mathrm{He} /{ }^{4} \mathrm{He}\right)$ in the mantle $(8 \mathrm{Ra}$, where the atmospheric ${ }^{3} \mathrm{He} /{ }^{4} \mathrm{He}$ is $\left.1 \mathrm{Ra}\right)$ is much higher than that in the crust $(<0.1 \mathrm{Ra})$, resulting in higher ${ }^{3} \mathrm{He} /{ }^{4} \mathrm{He}$ of magma than $1 \mathrm{Ra}$. Pre-eruptive ${ }^{3} \mathrm{He} /{ }^{4} \mathrm{He}$ rises have been reported in some volcanoes, suggesting increase in magmatic He supplies preceding the eruptions [e.g., 1]. The Kusatsu-Shirane volcano is an active stratovolcano consists of three pyroclastic cones, Mt. Shirane, Mt. Ainomine, and Mt. Motoshirane. To detect possible variations corresponding to the volcanic activity, we have analyzed noble gas isotopic compositions of three fumaroles on the northern flank of Mt. Shirane since July 2015.

After a phreatic eruption on 23 January 2018 at Mt. Motoshirane, the average ${ }^{3} \mathrm{He} /{ }^{4} \mathrm{He}$ (corrected for atmospheric $\mathrm{He}$ contamination by ${ }^{4} \mathrm{He} /{ }^{20} \mathrm{Ne}$ ) increased from the pre-eruptive values of 7.3-7.4 Ra (April 2017 to November 2017) to 7.6-8.0 $\mathrm{Ra}$, implying increase in magmatic He supply after the eruption.

The higher ${ }^{40} \mathrm{Ar} /{ }^{36} \mathrm{Ar}$ of the samples (up to 309 ) than the atmospheric $\mathrm{Ar}$ (296) indicate the presence of excess ${ }^{40} \mathrm{Ar}$ $\left({ }^{40} \mathrm{Ar} *\right)$. The high ${ }^{3} \mathrm{He} /{ }^{4} \mathrm{He}$ indicates ${ }^{40} \mathrm{Ar} *$ is dominantly derived from the mantle. Since ${ }^{3} \mathrm{He}$ of the samples is almost entirely of mantle origin (>99\%), both ${ }^{3} \mathrm{He}$ and ${ }^{40} \mathrm{Ar}^{*}$ are mostly degassed from the magma. Therefore, the ${ }^{3} \mathrm{He} /{ }^{40} \mathrm{Ar} *$ can be used as a tracer for the variation of the magmatic $\mathrm{He} / \mathrm{Ar}$.

The ${ }^{3} \mathrm{He} /{ }^{40} \mathrm{Ar} *$ of the fumarolic gases episodically increased after the eruption, which are three to four times higher than the pre-eruptive value of $\sim 3 \times 10^{-5}$. Noble gases in a gas phase of a silicate melt are fractionated as functions of solubilities and melt vesicularity, where noble gases with lower solubilities are preferentially partitioned into the gas phase, and the degree of fractionation decreases with increasing vesicularity [2]. Therefore, the increase in ${ }^{3} \mathrm{He} /{ }^{40} \mathrm{Ar} *$ is attributable to the increased vesicularity of degassing magma beneath the KusatsuShirane volcano since the solubility of Ar in a silicate melt is lower than $\mathrm{He}$ [3].

[1] Padrón et al. (2013) Geology 41(5), 539-542. [2] Jambon et al. (1986) GCA 50, 401-408. [3] Lux (1987) GCA 51, 15491560 . 